\title{
Fatigue failure of welded connections at orthotropic bridges
}

\author{
Z.H. Qian, D. Abruzzese \\ University of Rome "Tor Vergata", Department of Civil Engineering, Rome (Italy)
}

Riassunto. Le piastre ortotrope sono state applicate ai ponti di grande luce a partire dal periodo immediatamente successivo alla Seconda Guerra mondiale a causa dei numerosi vantaggi che esse presentano, come il peso contenuto, l'elevata resistenza, il ridotto numero di connessioni con l'impalcato, la durabilità, la rapidità costruttiva e l'economia dovuta alla manutenzione durante il ciclo di vita. Lo studio della fatica nelle piastre ortotrope è iniziato circa venti anni fa, da quando sono state diagnosticate le prime rotture per fatica. Da allora sono stati condotti un vasto numero di studi e indagini, ottenendo risultati interessanti. Si è scoperto che la maggior parte delle rotture per fatica si verificano in corrispondenza delle connessioni saldate, ovvero le giunzioni rib-to-deck, rib-to-diaphragm, e rib-to-diaphragm-to-deck (plate) (RDDP). Questa tipologia di connessioni è sensibile alla nascita di fratture per fatica dovute agli accumuli di tensione ed alle tensioni residue nelle connessioni saldate. In questo articolo viene presentato e analizzato un caso studio di rottura a fatica nelle connessioni saldate, dove è più probabile una frattura, attraverso una modellazione numerica di una piastra ortotropa con un software ad elementi finiti (FE). Inoltre viene affrontato il tema del miglioramento delle tecnologie adottate per limitare i problemi di fatica. I risultati di queste analisi possono rappresentare un proficuo contributo per la progettazione a fatica delle piastre ortotrope.

ABSTRACT. Orthotropic decks were applied to the long span bridges after World War II due to several advantages, such as light weight, high strength, few deck joints, durability, rapid construction, life-cycle economy. The fatigue problem of orthotropic decks was realized twenty years ago since fatigue failure was found. In the past two decades large amount of studies and investigations were carried out and fruitful achievements were obtained. It was found that most of the fatigue cracks were occurred at the welded connection details, such as rib-to-deck plate, rib-to-diaphragm, and rib-to-diaphragm-to-deck plate (RDDP). These connections are sensitive to fatigue cracking due to high concentrated stress and residual stress at welded connections. In this paper practical fatigue failure cases at the welded connections, ease to occur fatigue cracking, are presented, and analyzed through a numerical modeling of orthotropic deck via FE (finite element) software. Furthermore, the improvement technologies of fatigue are also discussed. The results of the analysis can be contributed to the evaluation of the fatigue design for the orthotropic deck.

KEYWORDS. Fatigue failure; Welded connection; Orthotropic deck; Numerical modeling; Rib-to-deck plate connection.

\section{INTRODUCTION}

$\mathrm{F}$ atigue cracking is a common problem in steel structures for a long time due to the existing of welded connections. According to the practical cases, most of fatigue failures occurred at welded components since high residual stress and inherent defects existed [1].

Since from 1960 a number of bridge structures in America and Europe have experienced fatigue cracking which sometimes results brittle fractures, fatigue problem in steel bridges has been started to be investigated for many years and produced fruitful achievements. 
From the British Standard BS5400 is one of the most important specifications in the last century [2], and recently, some new specifications or standards were accomplished, such as Eurocode3 (2004) [3] and AASHTO (2005) [4]. These specifications provide a mass of information to design steel bridges. Among of these, Eurocode 3 and AASHTO already have some specific guidelines to orthotropic deck bridges. S-N curves in Eurocode 3, for fatigue design, are shown in Fig. 1.

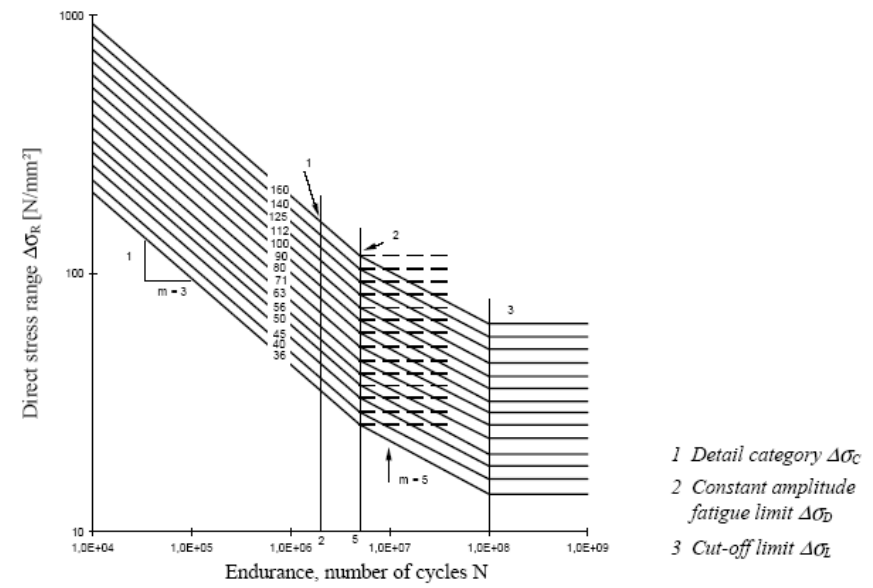

Figure 1: Fatigue strength curves for direct stress ranges (Eurocode3, 2004).

The orthotropic deck is consisted by a deck plate supported in two mutually perpendicular directions by transverse diaphragms (or crossbeam) and longitudinal stiffeners (or ribs). It is effectively an ORTHOgonal anisoTROPIC (orthotropic) deck.

Orthotropic deck is widely utilized for long span bridges in recent decades with the development of computing methodologies and fabricating technologies. It was first used in Germany after the Second World War in order to reduce the construction material, since steel being in short. Nowadays, orthotropic deck bridges are very popular in Europe, particular in Germany. Meanwhile, more and more orthotropic bridges are being built in China, Japan, U.S.A., and other countries. Orthotropic deck has many advantages, main of one is the light weight, high strength, few deck joints, durability, rapid construction and life-cycle economy.

However, fatigue problem is unavoidable at orthotropic deck bridges due to the complex structure and the large number of welded connections. Fig. 2 shows a summary of welded connection details at orthotropic deck bridges [5]. It is obvious that most of these are potentially liable to cause fatigue cracking taking account into concentrated stress and residual stress in welded connections.

In the past years various technologies were studied to improve the fatigue performance of welded joints. The fatigue life can be increased through surface treatment, reducing residual stress as well as optimizing design of structure. Among of these, peening, as a cold treatment technology, is one of the most widely utilized in engineering, bringing better surface properties and producing beneficial compressive stress [6]. Both of them can improve the fatigue strength of welded connections. This last technology is still highly improving.

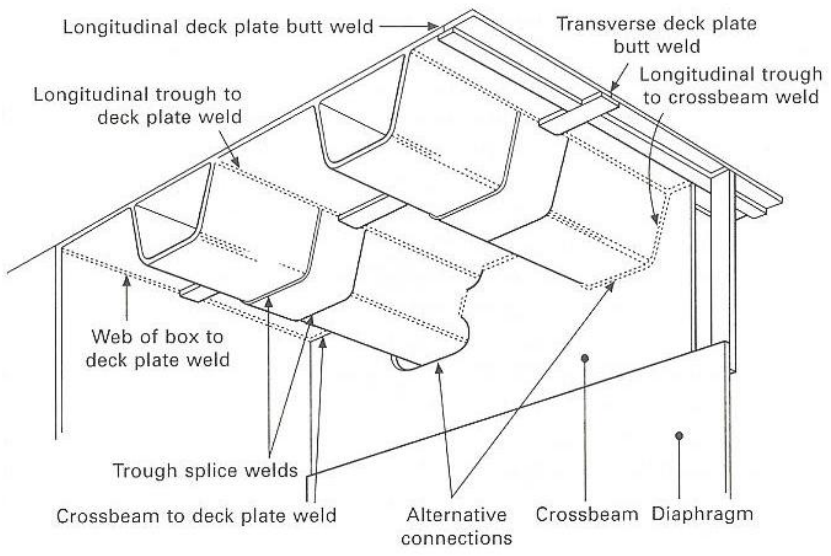

Figure 2: Main welded connections in a typical orthotropic bridge deck (Gurney, 2006) 
In this paper, the fatigue failures at orthotropic deck bridges are discussed based on the previous investigations. The sensitive connection details to fatigue cracking, rib-to-deck plate, rib-to-diaphragm and rib-to-diaphragm-deck plate, are emphasized through practical cases and numerical analysis. Furthermore, the three improvement techniques, shot peening, fluid bed peening (FBP) and ultrasonic impact treatment (UIT) are detailed presented. This study aims to contribute to the design and reinforcement of orthotropic deck bridges.

\section{RIB-TO-DECK PLATE CONNECTION}

$\mathrm{R}$

ib-to-deck plate connections are submitted to local transverse bending moments and are therefore susceptible to fatigue cracking. The connections have been studied for a long time, particular in recent years. Fig. 3 shows fatigue cracking at rib-to-deck plate connection [7].

The fatigue tests to rib-to-deck plate connection were carried out by Janss in 1980 in Belgium [8]. Thirty-three small test specimens were manufactured and tested at a frequency of $4 \mathrm{~Hz}$.

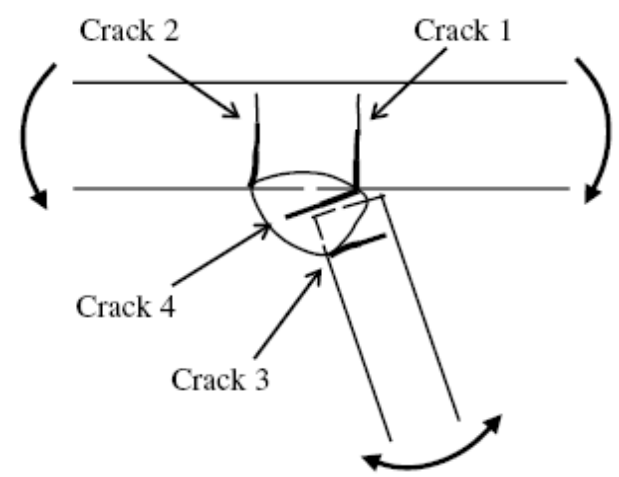

Figure 3: Fatigue cracks at rib-to-deck plate connection (Xiao, 2008).

Through the investigation, it was concluded that the stress range at two million cycles of the transverse stresses at the weld toe in the rib is equal to $80 \mathrm{~N} / \mathrm{mm}^{2}$ when trapezoidal ribs with a thickness of $6 \mathrm{~mm}$ are welded to deck plates with a thickness of $12 \mathrm{~mm}$ and the gap between the rib and the deck plate does not exceed $0.5 \mathrm{~mm}$. The stress range $\left(80 \mathrm{~N} / \mathrm{mm}^{2}\right)$, mentioned above, is certainly a lower limit due to the poor quality of the welds of the test pieces.

Based on the investigations of Janss and the others, ECSC research carried out on the optimization of the welding procedure (automatic welding) and the influence of a gap, 0 or $2 \mathrm{~mm}$, between the rib and the deck plate [9]. The specimens used in the ECSC experiments were welded with automatic submerged arc welding in an industrial situation. It was found that full penetration welds with a lack of penetration less than $1 \mathrm{~mm}$ can nearly be achieved without edge preparation. Meanwhile, the fatigue strength significantly increases when using submerged arc welding, which allows larger penetration and larger throat of the weld.

With the development of the compute technology, more and more numerical studies are put into practice. Finite element analysis (FEA) provides more results to details compared to the traditional method, such as P-E method. Stress distributions of three different loadcases at the deck plate were shown in Fig. 4 [10]. From the figure, two obvious differences can be concluded. The first one is that the range of high stress is much different, and loadcase1 is larger than the other two. The second one is that both maximal and minimal stresses of loadcase 2 and loadcase 3 are much higher than loadcase1. The stresses far from the vehicle appear like waves due to the restriction of longitudinal ribs, and are almost zero. Another important point should be noted is that the peak stresses of all these there different loadcases produced near or exactly at the rib-to-deck plate connections. For loadcase1, symmetrical loading, both maximal and minimal stress are exactly at the connections, while for loadcase 2 and loadcase 3 , asymmetrical loading, the maximal stresses are produced at the middle of the rib and maximal negative stresses occur at the rib-to-deck plate connections. This can explain why plenty of fatigue cracks occur at this position in laboratory tests and actual projects.

Submodel based on the global FE model is necessary to obtain the accurate results to the fatigue design. Welded joints are not considered in global numerical model, therefore, a submodel is needed to describe the weld geometry influence to orthotropic deck. In comparison, few researches are carried out on the submodel analysis of the rib-to-deck plate connection $[7,11]$. High compressive stresses are resulted in the weld toe and root regions, which is due to the large local load used and the abrupt geometry transition modeled in the linear elastic FEA. This analysis may be useful for practical 
design when choosing the detail geometry, the structural material and the welding technique and requirements. Fig. 5 shows a submodel of rib-to-deck plate connection with a crack [11].

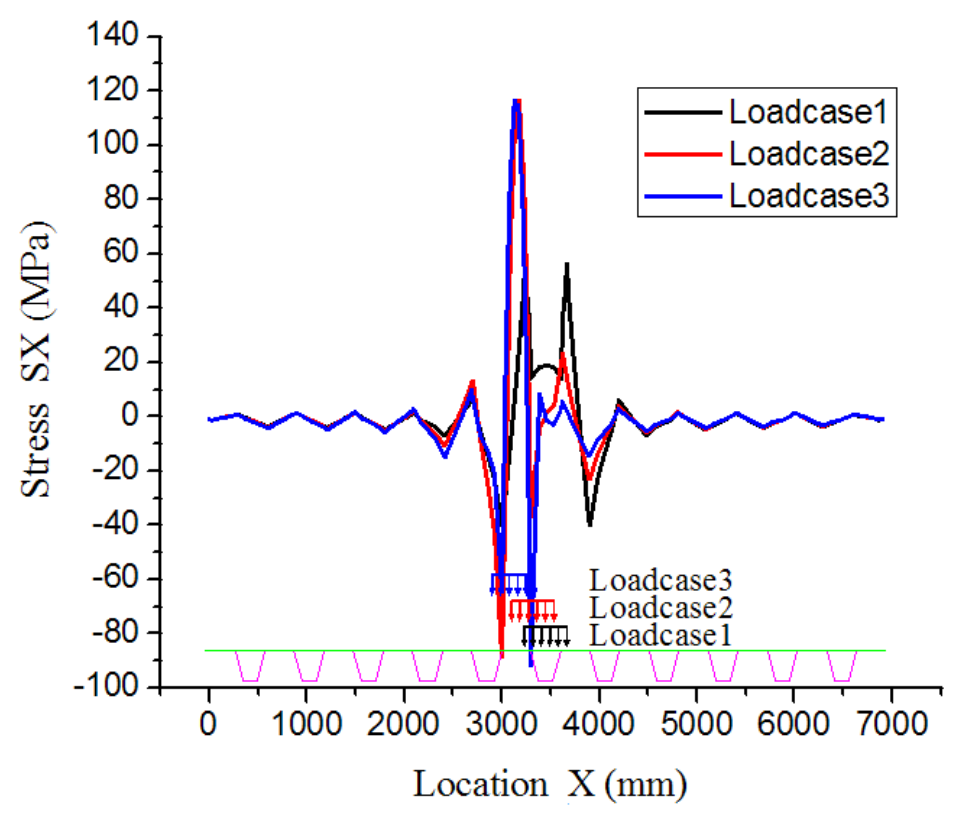

Figure 4: Stresses at the center deck plate of the middle span (Abruzzese et al., 2008)

\section{RIB-TO-DIAPHRAGM CONNECTION}

$\mathrm{R}$ ib-to-diaphragm connection is one of the most complex joint in the orthotropic deck. Cutout has a significant influence to the stress performance at the diaphragm, especially the area near the cutout. The previous investigations have demonstrated that peak stresses occur at the rib-to-diaphragm connections easily due to concentrated influence.

Numerical as well as experimental work at ECSC research showed a reduction of the stress concentration at the edges of cutout by increasing the notch radius of cutout [12]. After investigating different continuous types of rib-to-diaphragm connection of railway bridges in the laboratory, Haibach et al. proposed a new shape of cutout for rib passing through diaphragm [13], and it is applied in Eurocode3 (2004).

Fatigue tests were carried out at Delft University of Technology by Kolstein et al [14]. The results demonstrated that fatigue life of the continuous rib-to-diaphragm connection without cutout resulted in a longer fatigue life than the connection with cutout. Furthermore, the fatigue life of the rib-to-diaphragm connection with additional cutouts is strongly affected by high shear stresses in the diaphragm. It was presented as well that besides quality aspects the durability of the rib-to-diaphragm connection is mainly restricted, due to shortcomings in design with respect to the underestimation of high shear forces (out-of-plane stress).

ATLSS research center of Lehigh University has investigated the fatigue performance at cutout more than 10 years, particularly at rib-to-diaphragm connection $[15,16]$. Both field measurements and laboratory tests were carried out to Williamsburg Bridge and Bronx-Whitestone Bridge in New York City under supervision of Fisher. From the long term remote monitoring of the Williamsburg Bridge orthotropic deck diaphragm, it is found that a number of stress cycles exceed the constant-amplitude fatigue limit for Category $\mathrm{C}$, which was found to be applicable to the rib-to-diaphragm welded joint at the cutouts. Meanwhile, both in-plane and out-of-plane stresses were studied in ATLSS researches. It is inplane stress, not out-of-plane stress, dominant the stress range at diaphragm. However, out-of-plane bending can influence the fatigue behavior of rib-to-diaphragm connection significantly. FE method was used to analyze the influence of cutout geometry (with bulkhead) to welded rib-to-diaphragm connections by Connor [17]. Parameters considered included overall cutout shape, cutout depth, diaphragm plate thickness, and deck plate thickness. Results of this study indicate that larger cutout geometries offer less resistance to out-of-plane displacements induced by longitudinal ribs rotations. However, cutouts that are excessively deep will increase in-plane stresses at the welded rib-to-diaphragm 
connection. Fig. 6 shows cracks in weld options at/near rib-to-diaphragm connections of the Williamsburg Bridge and the Bronx-Whitestone Bridge [18].

Based these investigations, the stresses at rib-to-diaphragm connections (without bulkhead) under different loadcases to diverse shapes of cutout were studied [19]. The numerical analysis clearly demonstrated that different load locations influence the stress status of diaphragm greatly, and peak stresses occur at the rib-to-diaphragm connections or rib-todiaphragm-deck plate (RDDP) connections, see Fig. 7.
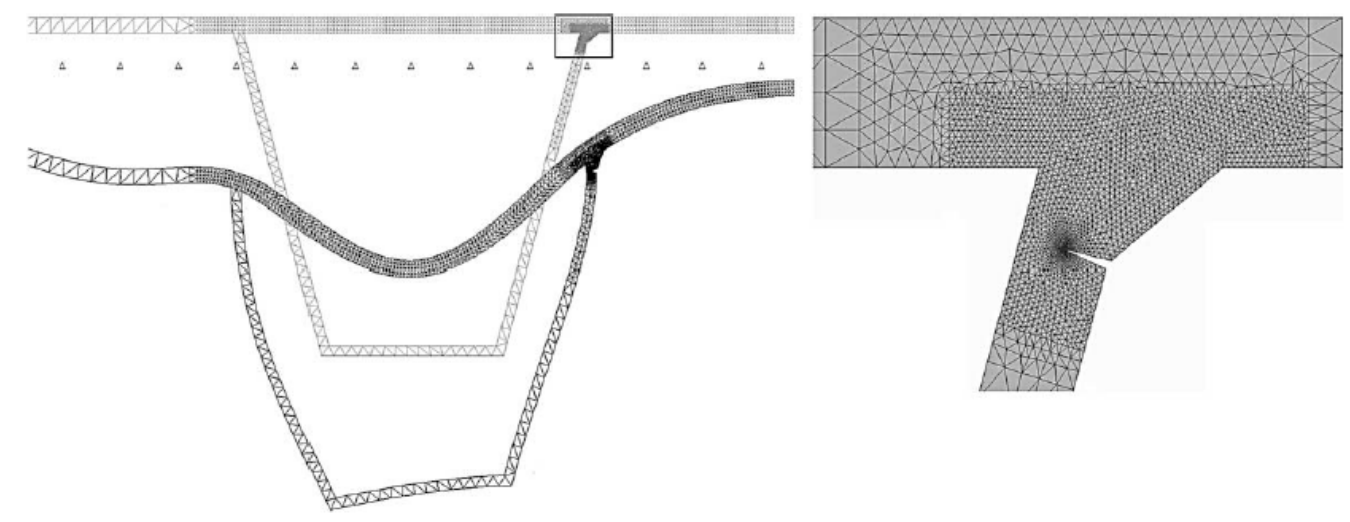

Figure 5: FE model of submodel analysis (Kiss, 2002).

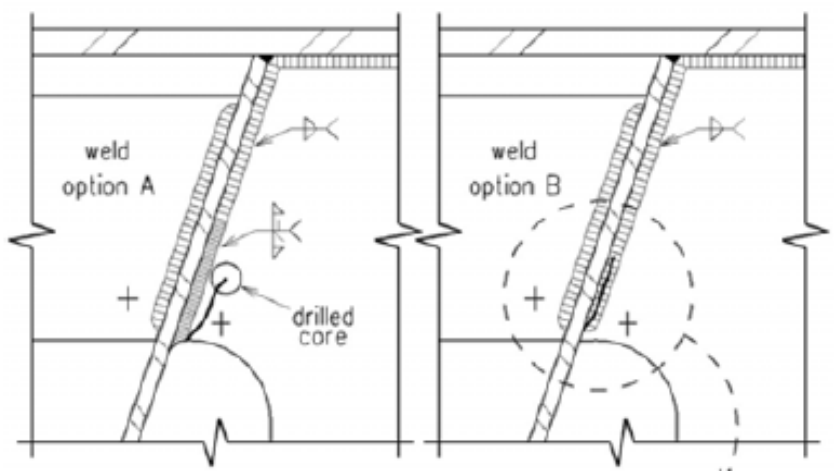

Figure 6: Cracks in weld options at near rib-to-diaphragm connection (Tsakopoulos, 2005).

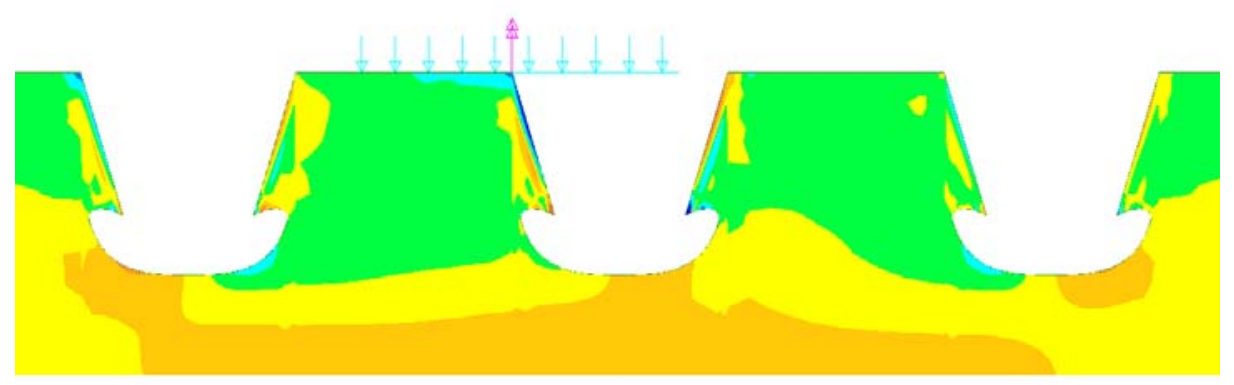

Figure 7: Stress distribution at diaphragm (Abruzzese et al., 2008).

\section{RIB-TO-DIAPHRAGM-TO-DECK PLATE (RDDP) CONNECTION}

I

$\mathrm{n}$ recent, rib-to-diaphragm-to-deck plate connection is found to be another sensitive place to produce fatigue cracking $[10,20]$. Based on the numerical analysis, it is found that peak stresses are produced at RDDP connections, and as well the out-of-plane stress should be considered to the fatigue design. 
Fig. 8 shows that the cracks developed at the RDDP detail are not typical root crack opening mechanisms. The practice has been to use normal stress, at the bottom of the deck plate, facing the root, assuming a category D (in AASHTO). This detail may, in cases of simple beam, be cycled in compression, the question of the rate of propagation of this detail calls for answers, as does the case for a cantilevered deck.

\section{FATIGUE IMPROVEMENT TECHNIQUES}

$\mathrm{H}$ igh tensile residual stress and initial defect exist in as-welded joints in the welded region as a result of the welding process. Advanced technology can reduce defects in weld, while a great benefit can be realized if compressive residual stresses are introduced. In general, fatigue improvement methodologies can be categorized as follows: (1) introduce beneficial compressive stress; (2) reduce stress concentration; (3) remove defects in components; (4) increase the rigidity in the connection. A summary of the various improvement techniques are presented in Fig. 9.

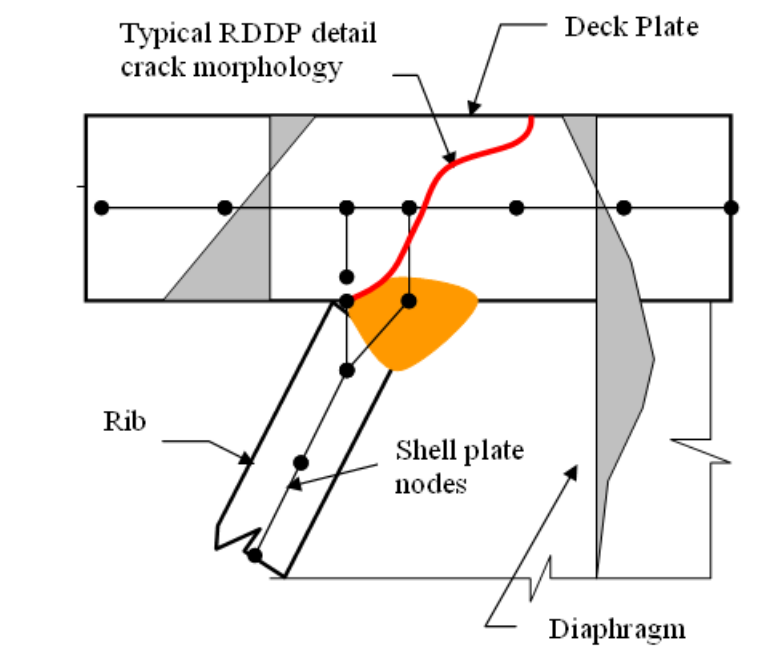

Figure 8: Fatigue cracks at RDDP connection (Camo, 2008).

\section{Traditional peening}

Peening is conventional and economy treatment method to improve the fatigue strength to welded connection. It includes various peening, such as shot peening, hammer peening, needle peening, fluid bed peening, ultrasonic peening, laser peening. Among of these, shot peening is most widely studied and applied. The effectiveness of shot peening is affected by many variables, the control of which are cumbersome and impractical, therefore only two parameters are used to specify the process, Almen intensity and coverage [21]. The major advantage of shot peening is that it covers area at low cost, however, care must be taken to ensure that the shot size is small enough to reach the bottom of all undercuts and weld inter-pass notches. It was reported by Maddox that an increase of $33 \%$ in the fatigue strength at two-million cycles of joints with longitudinal attachments and fabricated from 260 and $390 \mathrm{MPa}$ yield strength while the improvement was $70 \%$ for higher strength QT steels.

\section{Fluid bed peening (FBP)}

FBP technique is relatively novel treatment to coat metal substrates, change the surface properties, and induce microstructural changes. Specimens in fluid bed machine are kept in a fixed position on the inner bed, are subjected to strikes from abrasive grains driven by the fluid onto their surfaces. The investigations by Barletta et al. [22, 23] showed a progressive change in both the surface topography of the metal (roundness, roughness and aesthetic aspect) and in superficial properties (surface hardness, residual stress, density of the dislocations) can be induced. Furthermore, progressive smoothing of specimen surface associated with remarkable material removal can be expected, even at low temperature (Fig. 10).

After FBP treatment the delay of crack initiation and crack propagation can be expected. The investigations showed as well peening time and alternating stresses were the only two important experimental factors. Therefore, FBP technique is more ease to control because less operational parameters are demanded. 


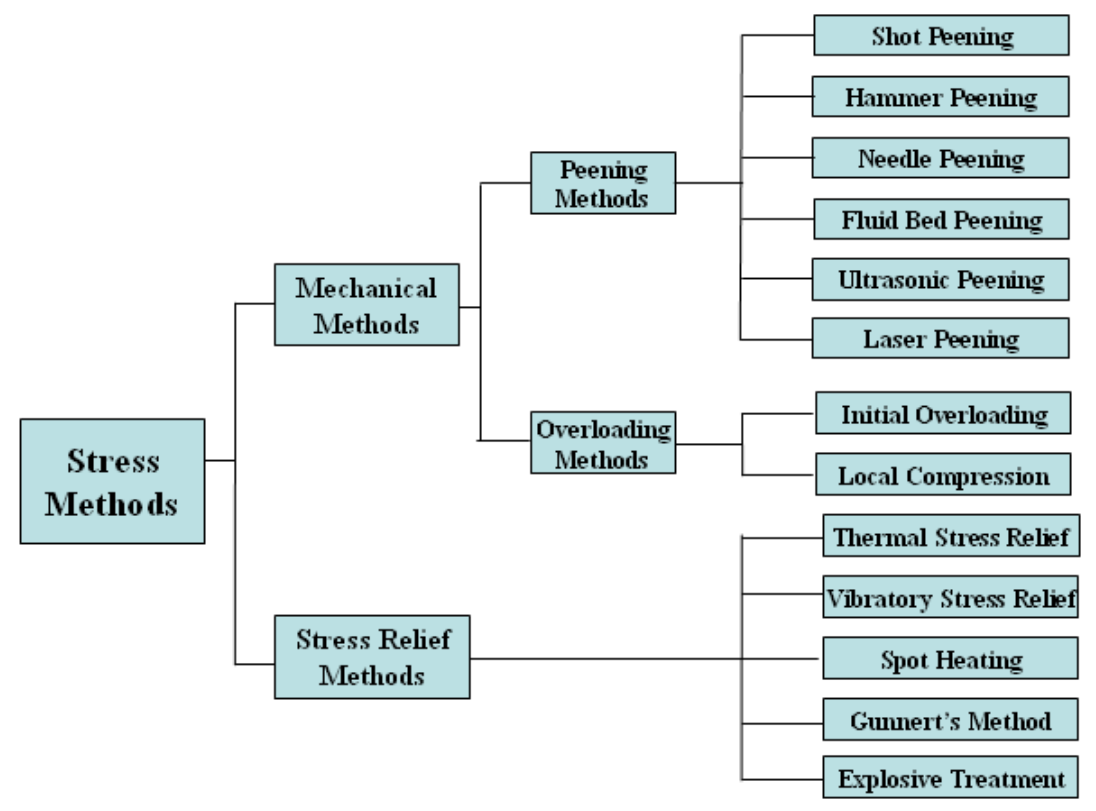

Figure 9: Fatigue improvement techniques.

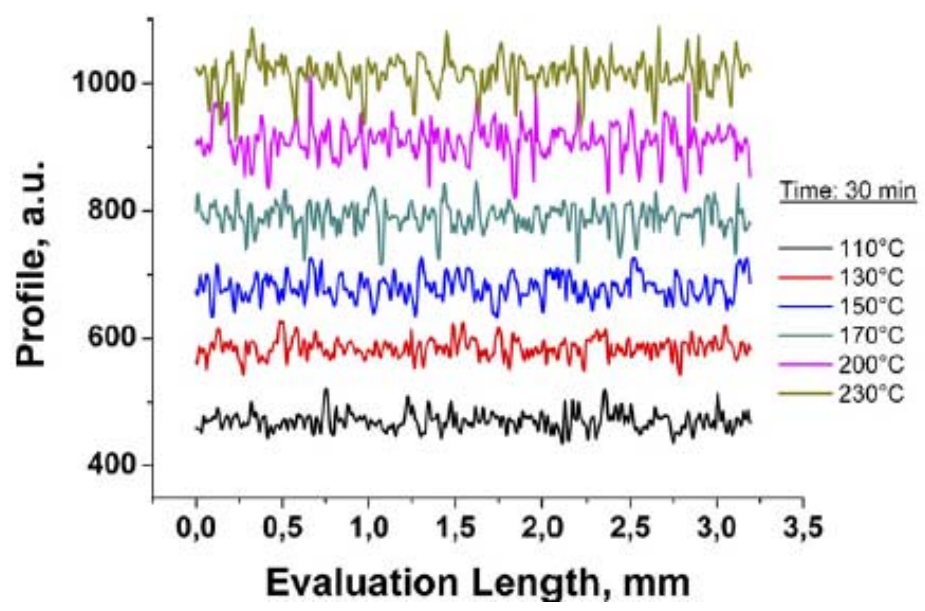

Figure 10: Surface properties after FBM treatment at different temperature (Barletta, 2007).

\section{Novel techniques}

Ultrasonic impact treatment (UIT) and laser shock peening are two new techniques to improve the fatigue life for steel structure. It is revealed by Lehigh University that the peak compressive residual stress induced UIT exceeded the yield stress of the base material near the sample surface [24]. The depth of compressive stress layer in base metal was 1.5-1.7 $\mathrm{mm}$ for UIT. The induced compressive residual stresses benefit to increase the threshold value of stress intensity factor range, $\Delta K_{t h}$, for fatigue crack initiation and early propagation. Laser peening is an emerging surface treatment technology that is an extension of shot peening. Compared to shot peening, laser peening indicates a significant increase in fatigue life based on the laboratory tests to the native welded specimens [25].

\section{CONCLUSIONS}

$\mathrm{T}$ his paper reviewed the fatigue failures at welded connections of orthotropic deck, and presented several improvement techniques. Stress performance of orthotropic deck is complex due to high concentrated stress, residual stress and out-of-plane stress. The fatigue behaviors of some welded connections are still in the dark, and 
are necessary to carry out further researches. Furthermore, more applicable technologies are needful for the fatigue design and the repairing of orthotropic deck.

\section{REFERENCES}

[1] J.W. Fisher. Fatigue and Fracture in Steel Bridges. John Wiley\&Sons, (1984).

[2] BS5400, Steel, Concrete and Composite Bridge-Part 10: Code of Practice for Fatigue, (1980).

[3] Eurocode 3: Design of Steel Structures, Part 1.9: Fatigue, (2004).

[4] AASHTO LRFD Bridge Design Specifications, (2005).

[5] T. Gurney. Cumulative damage of welded joints. CRC Press, (2006).

[6] L. Bertini, V. Fontanari, G. Straffelini, Int. J. of Fatigue, 20(10) (1998) 749.

[7] Z. Xiao, K. Yamada, S. Ya, X. Zhao, Int. J. of Fatigue, 30(8) (2008) 1387.

[8] J.Janss., J. of Constructional Steel Research, 9 (1988) 147.

[9] M.H. Kolstein, J. Wardenier, J.R. Cuninghame, C. Beales, A. Bruls, E. Poleur, S. Caramelli, P. Croce, J. Carracilli, B. Jacob, J.S. Leendertz, A. Bignonnet, Le Pautremat, H.P. Lehrke, Welding in the world, 38 (1996) 175.

[10] D. Abruzzese, Z.H. Qian. Fatigue Problems for Orthotropic Deck Bridges. Handling Exceptions in Structural Engineering: Robustezza Strutturale, Scenari Accidentali, Complessità di Progetto";University of Rome "La Sapienza", Italy: DOI: 10.3267/HE2008, (2008).

[11] K. Kiss, L. Dunai, Computers and Structures, 8 (2002) 2321.

[12] H. Lehrke, IABSE: Remaining Fatigue Life of Steel Structures, ETHHONGGERBERG, Zurich, 59 (1990) 133.

[13] S.J. Maddox. The fatigue behavior of trapezoidal stiffener to deck plate welds in orthotropic bridge decks. TRRL Report SR96UC, Transport Research Laboratory, Crowthorne, (1974).

[14] M.H. Kolstein, J.S. Leendertz, J. Wardeenier, Nordic Steel Construction Conference, Sweden, (1995).

[15] W. J. Bocchieri, J.W. Fisher. Williamsburg Bridge replacement orthotropic deck as-built fatigue test. ATLSS Report No. 98-04, (1998).

[16] R.J., Connor, J.W., Fisher. Results of field measurements on the prototype orthotropic deck on the Bronx-Whitestone Bridge. ATLSS Report No. 04-03, (2004).

[17] R.J. Connor, J. of the Transportation Research Board, 1892 (2004) 78.

[18] P.A. Tsakopoulos, J.W. Fisher, Steel Structure, 5 (2005) 211.

[19] D. Abruzzese, A. Grimaldi, Z.H. Qian, International Orthotropic Bridge Conference, U.S.A. (2008) 256.

[20] S. Camo, Q. Ye, R.C. Prior, V. Pandya, International Orthotropic Bridge Conference, U.S.A., (2008) 573.

[21] K.J. Kirkhope, R. Bell, L. Caron, R.I. Basu, K.-T. Ma. Marine Structures, 12 (1999) 447.

[22] M. Barletta, V. Tagliaferri. Int. J. of Machine Tools \& Manufacture, 46 (2006) 271.

[23] M. Barletta, G. Bolelli, S. Guarino, L. Lusvarghi, Progress in Organic Coatings, 59 (2007) 53.

[24] X. Cheng, J. W. Fisher, H. J. Prask, T. Gna" upel-Herold, B. T. Yen, S. Roy. Int. J. of Fatigue, 25 (2003)1259.

[25] O. Hatamleh, J. Lyons, R. Forman, Fatigue Fract. Engng.Mater. Struct., 30 (2007) 115. 